\title{
Organelle Cooperation in Stem Cell Fate: Lysosomes as Emerging Regulators of Cell Identity
}

\author{
Lisa M. Julian ${ }^{1 *}$ and William L. Stanford ${ }^{2,3,4,5 *}$
}

${ }^{1}$ Department of Biological Sciences, Simon Fraser University, Burnaby, BC, Canada, ${ }^{2}$ Regenerative Medicine Program, Ottawa Hospital Research Institute, Ottawa, ON, Canada, ${ }^{3}$ Department of Cellular and Molecular Medicine, University of Ottawa, Ottawa, ON, Canada, ${ }^{4}$ Ottawa Institute of Systems Biology, Faculty of Medicine, University of Ottawa, Ottawa, ON, Canada, ${ }^{5}$ Department of Biochemistry, Microbiology and Immunology, University of Ottawa, Ottawa, ON, Canada

\section{OPEN ACCESS}

Edited by:

Anthony Scimè,

York University, Canada

Reviewed by:

Nuno Raimundo,

University Medical Center Göttingen,

Germany

David A. Hood,

York University, Canada

*Correspondence:

Lisa M. Julian

Imjulian1@gmail.com

William L. Stanford

wstanford@ohri.ca

Specialty section:

This article was submitted to

Stem Cell Research,

a section of the journal

Frontiers in Cell and Developmental

Biology

Received: 11 May 2020

Accepted: 17 June 2020

Published: 07 July 2020

Citation:

Julian LM and Stanford WL (2020)

Organelle Cooperation in Stem Cell

Fate: Lysosomes as Emerging

Regulators of Cell Identity.

Front. Cell Dev. Biol. 8:591.

doi: 10.3389/fcell.2020.00591
Regulation of stem cell fate is best understood at the level of gene and protein regulatory networks, though it is now clear that multiple cellular organelles also have critical impacts. A growing appreciation for the functional interconnectedness of organelles suggests that an orchestration of integrated biological networks functions to drive stem cell fate decisions and regulate metabolism. Metabolic signaling itself has emerged as an integral regulator of cell fate including the determination of identity, activation state, survival, and differentiation potential of many developmental, adult, disease, and cancer-associated stem cell populations and their progeny. As the primary adenosine triphosphate-generating organelles, mitochondria are well-known regulators of stem cell fate decisions, yet it is now becoming apparent that additional organelles such as the lysosome are important players in mediating these dynamic decisions. In this review, we will focus on the emerging role of organelles, in particular lysosomes, in the reprogramming of both metabolic networks and stem cell fate decisions, especially those that impact the determination of cell identity. We will discuss the inter-organelle interactions, cell signaling pathways, and transcriptional regulatory mechanisms with which lysosomes engage and how these activities impact metabolic signaling. We will further review recent data that position lysosomes as critical regulators of cell identity determination programs and discuss the known or putative biological mechanisms. Finally, we will briefly highlight the potential impact of elucidating mechanisms by which lysosomes regulate stem cell identity on our understanding of disease pathogenesis, as well as the development of refined regenerative medicine, biomarker, and therapeutic strategies.

Keywords: lysosomes, stem cell identity and fate, metabolism, neural stem cell (NSC), pluripotent stem cell (PSC), neural crest (NC), cancer stem cell (CSC)

\section{METABOLIC ORGANELLE NETWORKS REGULATE STEM CELL FATE}

Stem cell fate decisions, including the determination of cellular identity, are intimately linked to gene expression networks with each decision driven by wide-spread transcriptional changes (Walker et al., 2007; Julian et al., 2013, 2017b; Julian and Blais, 2015; Pinto et al., 2018; Abdolhosseini et al., 2019; Wells and Choi, 2019). Transcriptional regulation does not function in 
isolation, however. Cell fate decisions are heavily influenced by dynamic communication between the nucleus with multiple biological processes and signaling cascades involving macromolecule interactions at the cell membrane, throughout the cytoplasm, and within or on the surface of organelles (Shah et al., 1996; Zhou et al., 2009; Julian et al., 2013; Julian and Blais, 2015; Singh et al., 2015; Chen et al., 2016; Young et al., 2016; Khacho and Slack, 2017b; Chang et al., 2018; Obernier et al., 2018; Bahat and Gross, 2019; Jaiswal and Kimmel, 2019; Kinney et al., 2019; Shlyakhtina et al., 2019; Chang, 2020). The successful development, long-term homeostasis, and post-injury repair of organs and tissues is dependent on the pliability in cell fate decisions that these integrated biological networks permit. Yet, this flexibility can also give rise to the aberrant stem cell populations that underlie pathology in many diseases including tumor syndromes. This double-edged sword of cell fate pliancy is paralleled by dynamics in metabolic signaling pathways. It is therefore crucial to understand the breadth of regulatory processes and factors that contribute to the biological networks underlying metabolic control and to elucidate their impacts on cell fate.

\section{Metabolic Signaling Impacts Cell Identity}

Cellular metabolism is broadly defined by the numerous biochemical pathways that participate in the processing of nutrients including amino acids, carbohydrates, and lipids, into their primary molecular building blocks along with energy in the form of adenosine triphosphate (ATP). The ATP produced through metabolic pathways is necessary to fuel the myriad of biological processes that take place within a cell to support its growth and viability. Metabolic bioenergetic signaling pathways are closely integrated with organelle-based processes, which together focus on balancing anabolic and catabolic cellular activities (Thelen and Zoncu, 2017; Todkar et al., 2017; Gordaliza-Alaguero et al., 2019; Xia et al., 2019). Respectively, anabolism and catabolism function to drive the production versus degradation of biomass, which is necessary to balance cell and tissue growth, homeostasis, and survival. Metabolic pathways are highly interconnected and dynamic, focused on managing supply and demand of available energy and nutrient substrates in the face of ever-changing environmental conditions. While many bioenergetic pathways exist that contribute to ATP production, a cell can be classified based on its relative reliance on two over-arching processes: oxidative phosphorylation (OxPhos) and glycolysis. These processes drive differential rates of ATP production and a unique complement of metabolite by-products (Folmes et al., 2012; Zhang et al., 2018; Gordaliza-Alaguero et al., 2019; Intlekofer and Finley, 2019). Oxidative phosphorylation is linked to the mitochondrial electron transport chain (ETC) and fueled by energy precursors generated through the tricarboxylic acid cycle (TCA). Alternatively, glycolysis takes place in the cytoplasm and can provide pyruvate as a substrate to feed into the TCA or can permit fully anaerobic macromolecule metabolism.

In addition to the production of ATP, metabolic signaling is now known to exert wide-ranging effects within a cell and has in fact emerged as a primary biological process underlying the regulation of cell fate decisions in a wide range of cell types, including stem cell populations. These impacts are achieved through mechanisms that include regulation of transcription factor expression and localization, integration of metabolic networks with growth factor and developmental signaling pathways, and the production of cell type and context-specific metabolites that permit chemical modification of signaling cascades and epigenetic regulation of DNA and histone proteins (Chung et al., 2007; Khacho et al., 2016, 2019; TeSlaa et al., 2016; Young et al., 2016; Cliff et al., 2017; Khacho and Slack, 2017a,b; Zhang et al., 2018; Jaiswal and Kimmel, 2019). Specific patterns of bioenergetic pathway activation influence cell fate decisions including the maintenance of self-renewal, induction of differentiation, homeostasis, activation state, and regenerative potential of distinct stem cell populations. It is now an established concept that cell identity itself, the outcome of multiple fate decisions during lineage development, is closely connected with particular metabolic states.

The connection between metabolic state and cell identity is well appreciated in the context of in vitro pluripotent stem cells (PSCs), including maintenance of their self-renewing state and the initial establishment of induced PSCs (iPSCs) from somatic cells such as fibroblasts. Transition to a glycolytic state from an oxidative one typical of somatic cells is universally required for both the acquisition and maintenance of pluripotency, critical for activation of self-renewal programs and inhibition of differentiation (reviewed in Zhang et al., 2018; Figure 1). There are subtleties to this rule however, as "naïve" PSCs, which functionally resemble the inner cell mass of the pre-implantation blastocyst (Figure 1), employ both OxPhos and glycolysis. This is in contrast to "primed" PSCs, a more developmentally mature population resembling cells within the post-implantation epiblast, which are predominantly glycolytic (Folmes et al., 2011; Zhang et al., 2018). This shift in metabolic preference between naïve and primed PSCs is accompanied by distinct changes in the expression profiles of developmental genes, which actively regulate glycolytic and OxPhos signaling patterns (Zhang et al., 2018). Subsequently, differentiation of PSCs into downstream lineages that parallel the mammalian germ layers is typically associated with transition from a glycolytic state to a preferential reliance on OxPhos (Figure 1). The metabolite a-ketoglutarate (aKG), generated through the mitochondrial OxPhos-dependent TCA cycle, functions in naïve PSCs to drive self-renewal but in primed PSCs to accelerate differentiation, a biphasic role attributed to the direct effect of aKG on stage-specific histone and DNA demethylation patterns and consequently epigenetic gene regulation (Carey et al., 2015; TeSlaa et al., 2016). Thus, a differential preference for OxPhos versus glycolysis signaling, reflecting unique needs for exogenous nutrients, regulatory cofactors, and oxygen and energy demands, parallels and can actively drive transitions between distinct stem cell identities.

The specification of ectodermal neural stem cells (NSCs) represents an exception to the paradigm that exit from pluripotency requires reprogramming to an OxPhos-dependent state (Figure 1), as a preference for glycolytic metabolism is maintained. Unlike in PSCs, however, glycolytic metabolism in the developing ectoderm appears to be driven by a reliance on glutamine as a primary metabolic substrate (Lees et al., 2018; 

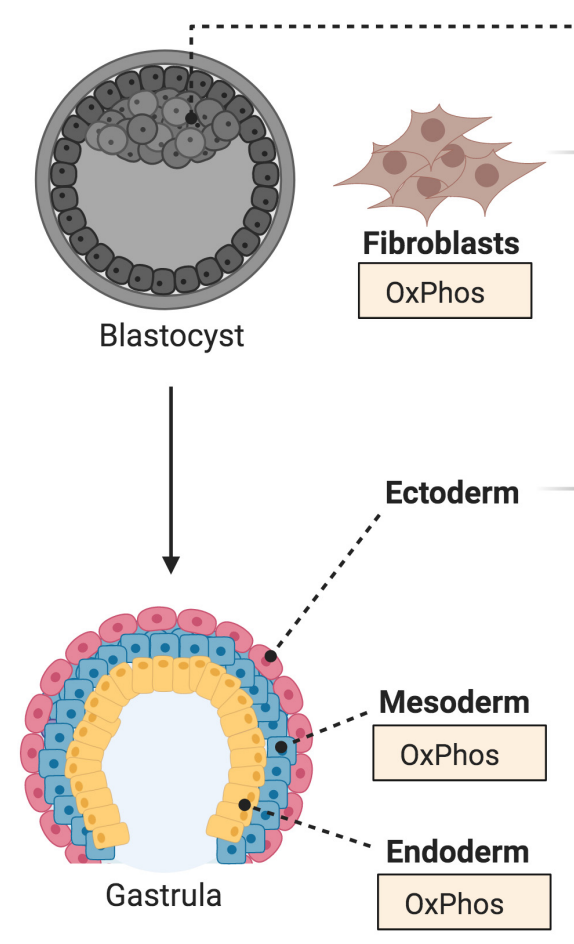

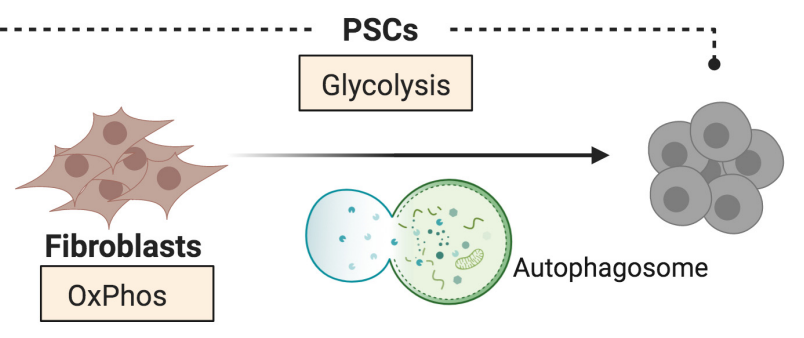

Lysosome-centered roles in cell identity determination

Autophagy signaling

Lysosome biogenesis, degradative activity

Roles unknown

FIGURE 1 | Lysosomes regulate stem cell identity transitions. Precise control of lysosome-autophagy signaling is required at an early stage during the reprogramming of somatic cells (i.e., fibroblasts) to induced pluripotent stem cells (PSCs) in vitro. In vivo, PSCs are located in the inner cell mass of the blastocyst during embryonic development, which gives rise to the gastrula from which the three primary germ layers (ectoderm, mesoderm, and endoderm) are born. Induction of ectodermal cells, specifically neural stem cells (NSCs) of the neuroectoderm, is accompanied by increased biogenesis and activity of lysosomes through mTORC1-regulated Micropthalmia/Transcription Factor E (TFE) nuclear organization. Alternatively, lysosome activation is associated with reduced endoderm and mesoderm differentiation. Given the prevalence of lysosome activity in various types of cancer, including those affecting the brain, it is possible that lysosomes drive the acquisition of cancer stem cell identity. The potential mechanisms are unknown. These stem cell identity transitions are also associated with metabolic reprogramming, whereby some cell types preferentially activate pathways requiring oxidative phosphorylation (OxPhos) whereas others rely on glycolysis. Cancer stem cells exhibit multiple strategies of metabolic reprogramming.

Harvey et al., 2019; Vardhana et al., 2019). Furthermore, a proper balance of NSC self-renewal versus differentiation following their initial specification, as well as homeostasis of adult NSC populations, depends on a shift toward the oxidative fatty acid metabolic pathway. In mature populations this occurs specifically in quiescent NSCs, which are critical for the longterm maintenance of the stem cell pool and for neurogenic capacity in the brain, but not "activated" proliferative populations (Knobloch et al., 2017; Leeman et al., 2018; Bankaitis and Xie, 2019). Strikingly, inhibition of a single metabolite malonyl-CoA, a factor that drives activation of the fatty acid oxidation pathway, is sufficient to force quiescent NSCs into a proliferative state in a manner dependent on activation of the bone morphogenetic protein (BMP) signaling pathway (Knobloch et al., 2017). This again demonstrates a direct effect of metabolic state on cell fate regulation and underscores the integration of metabolic networks with developmental signaling pathways.

\section{Organelle Cooperation in Cell Metabolism}

Metabolic pathways and the biological processes that fuel anabolic and catabolic activities are partitioned among distinct subcellular locations. Over the past decade, however, it has become increasingly clear that communication between organelles and cytoplasmic signaling pathways is critical for the dynamic regulation of bioenergetic networks that underlies cell and tissue homeostasis (reviewed in Schrader et al., 2015). The nucleus, mitochondria, endoplasmic reticulum (ER), and cellular vesicles (including lysosomes, autophagosomes, and peroxisomes) are historically defined, respectively, as regulators of gene expression, ATP production, protein and lipid production/export, and macromolecule degradation. Yet we now know that these organelles in fact exhibit multi-faceted roles within the cell, functionally and physically interacting with one another to cooperatively regulate processes that parallel or can directly impact metabolic control such as cell signaling, survival, immunity, and fate decisions.

Electron microscopy, immunofluorescence and time-lapse imaging analyses have revealed many organelles to be highly interconnected and dynamic structures (reviewed in Schrader et al., 2015; Lim and Zoncu, 2016). Regular fission and fusion events of mitochondria function to remodel their cristae and allow an exchange of intra-organelle and membrane components including ETC channel proteins, metabolites, calcium $\left(\mathrm{Ca}^{2+}\right)$, 
and other ions. These interactions are essential for bioenergetic integrity, and consequently for the regulation of multiple facets of tissue development and maintenance (Khacho et al., 2016, 2017; Baker et al., 2019). Likewise, lysosomes move between the peri-nuclear region and the cell membrane in response to energy signaling demands through the mTORC1 signaling pathway (Starling et al., 2016; Hao et al., 2018), and they undergo regular fission and fusion events with one another (Ballabio and Bonifacino, 2020). This leads to changes in organelle size, vesicle tubulation and subsequent reformation of lysosomes from these hybrid organelles, presumably mediating transfer of membrane and lumenal contents among the broader lysosome population. Though lysosome dynamics appear to be important for bioenergetics and cell homeostasis, the mechanisms and direct consequences of these activities are not well understood (Saffi and Botelho, 2019; Ballabio and Bonifacino, 2020). Lysosomes have also long been known to fuse with autophagosome vesicles which carry excess and damaged cellular materials to the lysosome's acidic lumen for degradation. Thus, lysosomes constitute the end point of the autophagy pathway, a ubiquitous cellular process critical for survival in the face of changing environments that impacts development, cell and tissue homeostasis, immunity, and disease predisposition (Chang, 2020).

In addition to "self-interactions," multiple organelles in fact cooperate with one another in ways that can impact metabolic circuits. An emerging field has focused on the effects that by-products of mitochondrial metabolism can impart within the nucleus, including reactive oxygen species and multiple metabolites generated through the series of redox reactions that fuel oxidative metabolism. Many such metabolites, including $\alpha \mathrm{KG}, \mathrm{NADH}$, and acetyl-coA, are produced through the TCA or in parallel pathways and subsequently function in the nucleus as co-factors for enzymes that regulate methylation and acetylation of DNA and histones. Mitochondrial metabolites can therefore significantly impact transcriptional regulation at an epigenetic level (Khacho et al., 2016; Harvey et al., 2019). This functional inter-organelle connection is a critical mechanism to control mitochondrial homeostasis and stability, as it permits activation of nuclear genes required for mitochondrial biogenesis. Disruption of mitochondria-nuclear connections can lead to DNA damage, calcium overload, developmental dysfunction, and disease including tumorigenesis (Guha and Avadhani, 2013; Cantó et al., 2015; Tu et al., 2018; Xia et al., 2019).

More recently, the lysosome has emerged as an organelle that also has direct functional connections to the nucleus. Dynamics of nutrient-sensing signaling complexes on the lysosome surface control the sub-cellular localization of the Micropthalmia/Transcription Factor E (MiT/TFE) family of transcription factors (herein referred to as 'TFE'), critical regulators of genes that drive lysosome biogenesis and metabolic reprogramming (Settembre et al., 2011, 2012; Young et al., 2016; Figure 2). Additionally, the lipase LIPL-4 promotes longevity in Caenorhabditis elegans by harnessing its degradative activity within the lysosome to establish a lipid-protein chaperone complex that translocates to the nucleus and promotes the transcriptional activity of NHR- 49 and NHR- 80 nuclear hormone receptors (Folick et al., 2015). Nuclear hormone receptors regulate the expression of genes related to mitochondrial metabolism and the oxidative stress response, a mechanism linked to organismal longevity due to downstream activation of mitochondrial ß-oxidation and ETC activity (Folick et al., 2015; Ramachandran et al., 2019). Biochemical and high throughput metabolomic analyses revealed that the nuclear complex generated by LIPL-4 in C. elegans is comprised of the lipid species oleoylethanolamide (OEA) and the lipid chaperone LBP-8. All three elements of this signaling pathway are structurally or functionally conserved in mammals (LIPL-4 and NHR- 80 are homologous to mammalian LIPA and HNF4, respectively; the mammalian lipid metabolism transcription factor PPAR $\alpha$ is activated by OEA) (Fu et al., 2003; Folick et al., 2015; Ramachandran et al., 2019), thus similar lysosome-nuclear signaling mechanisms are likely to impact cell fate determinant transcriptional programs in mammalian systems.

Physical connections between organelles can take place through either direct membrane fusions or membrane contact sites (MCSs) mediated through tethering proteins. These connections permit the transport of metabolites and signaling molecules, lipid moieties, and ions like $\mathrm{Ca}^{2+}$ and iron that function as cofactors for biochemical reactions (Sheftel et al., 2007; Schrader et al., 2015; Todkar et al., 2017; Xia et al., 2019). They also participate in mediating and stabilizing structural processes, such as fission-fusion dynamics of mitochondria and lysosomes and the maturation of endosomes, including their trafficking along microtubules and ultimate fusion with lysosomes (Friedman et al., 2013). Membrane contact sites were in fact first observed, between the ER and mitochondria, by electron microscopy half a century ago (Copeland and Dalton, 1959). Despite this long history, we are only recently beginning to understand the molecular mechanisms that regulate these connections and the specificity of their biological effects.

Recent work demonstrated that in order to promote vascular modeling in the brain, reactive astrocytes develop clusters of mitochondrial-ER contacts to drive $\mathrm{Ca}^{2+}$ uptake from the ER. This was shown to be dependent on the mitochondrial fusion protein Mitofusin 2 (Mfn2), and thus is linked to dynamics in mitochondrial structure (Göbel et al., 2020). We now know that multiple organelles establish MCSs with other membrane-bound organelles or cell structures. This includes between the plasma membrane and the ER, which regulates $\mathrm{Ca}^{2+}$ dynamics between the extracellular space and the ER, the dominant $\mathrm{Ca}^{2+}$ storage site in the cell. Lysosomes have been observed to form MCSs with multiple organelles, including the ER, peroxisomes, Golgi apparatus, and mitochondria (Schrader et al., 2015; Todkar et al., 2017; Xia et al., 2019; Figure 2). A tethering complex that mediates mitochondrial-lysosome MCSs has been identified in yeast, where it is an important regulator of cell growth and is activated and maintained in response to metabolic activity (Hönscher et al., 2014). Alterations in the abundance of organelle MCSs are observed in cases of aberrant metabolic regulation and metabolic disorders, and gene knockout studies of proteins that comprise MCSs have begun to reveal that the integrity of at least some of these contacts is indeed crucial 


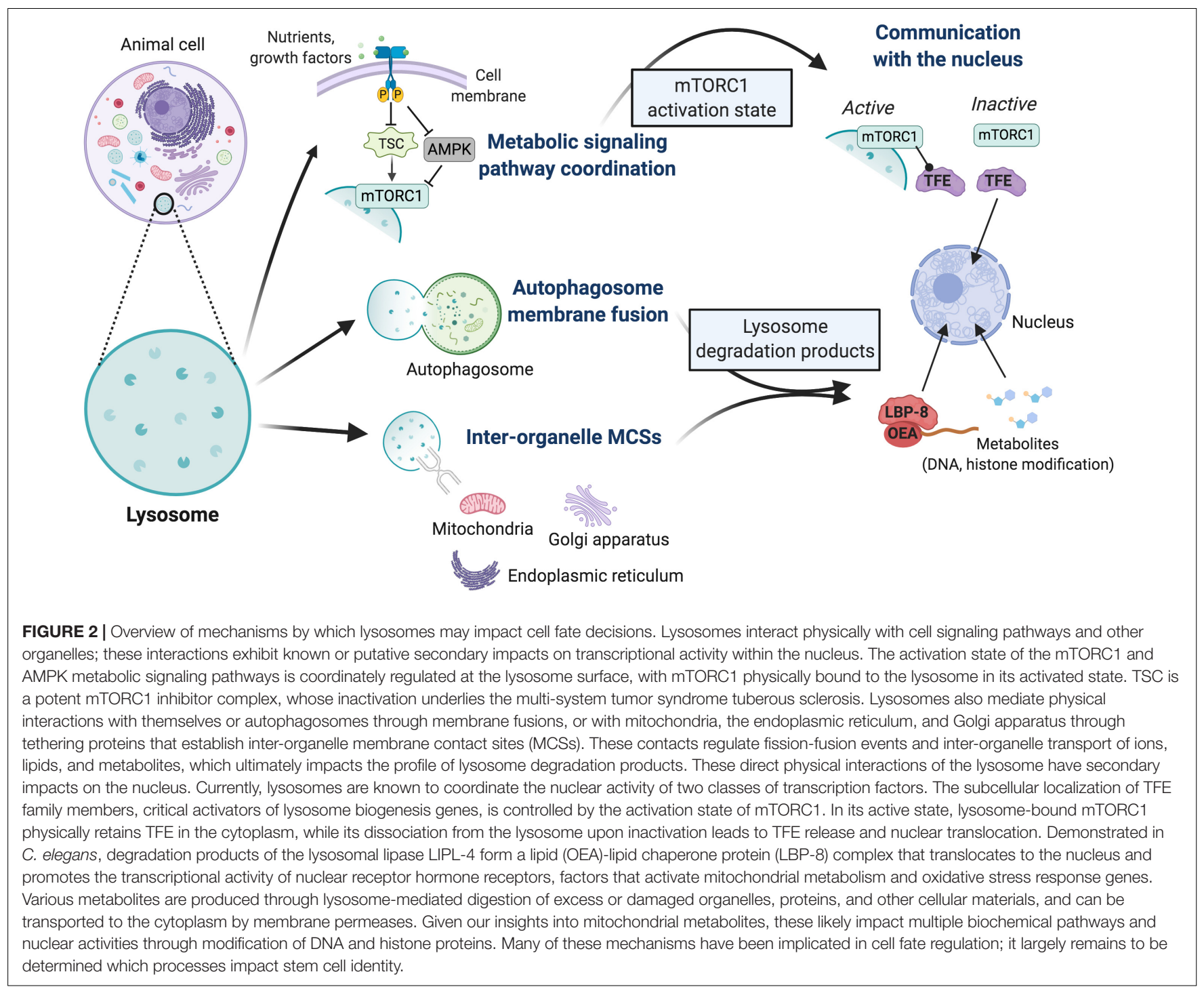

to proper metabolic regulation (Sebastián et al., 2012, 2016; Gordaliza-Alaguero et al., 2019).

\section{Organelle Inheritance and Cell Fate Determination}

Gene and resulting protein expression patterns ultimately define and maintain a cell's identity, and mitochondria are wellestablished regulators of gene expression programs. Alterations in mitochondrial content, fission and fusion dynamics, and signaling cascades including metabolite production and retrograde signaling to the nucleus has a profound impact on cell fate specification (Khacho et al., 2016; Khacho and Slack, 2017a). This encompasses broad populations including pluripotent, somatic and cancer stem cells (CSCs), from development through long-term homeostasis and aging. A compelling indicator that mitochondria play an instructive role in cell identity specification is that their segregation into the progeny of dividing stem cells has been observed to occur in a biased manner. For instance, during meiosis I of mammalian oocyte development mitochondria aggregate around the spindle pole, which will determine the plane of cell division. Upon division mitochondria are preferentially retained in the newly formed oocyte at the expense of the polar body, in a manner dependent on cell cycle progression and mitochondrial transport by the actin cytoskeleton (Dalton and Carroll, 2013). As the polar body is destined for degradation, this mechanism is thought to ensure the inheritance of mitochondria, and the consequent production of ATP and proper cell function, in cells destined to drive early embryo development.

Similarly, in budding yeast, mitochondria are partitioned in a biased manner at cell division such that the daughter bud cell receives a higher proportion of mitochondrial content at a cost to the mother cell (Böckler et al., 2017). As in mammalian oogenesis, this partitioning is dependent on fusion and transport of mitochondria on actin networks and is crucial for the maintenance of proper replicative lifespan of yeast bud cells. An elegant study that employed photoactivatable fluorescence tags 
as a relative measure of organelle age revealed that in actively expanding human mammary epithelial cultures, mitochondria exhibit biased distribution such that daughter stem cells with the highest potential for stemness receive predominantly young mitochondria (Katajisto et al., 2015). Genetic knock-down analyses targeting the structural fission proteins Parkin and Drp1 demonstrated that this regulated segregation also exploits fission-fusion dynamics.

As stem cells divide, molecular mechanisms converge to dictate whether their progeny will give rise to new-born stem cells through self-renewal, or instead to specialized differentiated cell types. One mechanism by which this is determined is regulation of the pattern in which cell fate determinant factors, including transcription factors, RNA molecules, signaling proteins, and organelles, are distributed among daughter cells (Venkei and Yamashita, 2018; Shlyakhtina et al., 2019). It is well established that stem cells divide with a spindle pole orientation that is either perpendicular to the surface of a defined stem cell niche or is at an altered angle relative to the niche. Though DNA is equally distributed between both daughter cells, the distribution of many cell fate determinants is polarized relative to the niche instead of the mitotic spindle pole. Therefore, perpendicular spindle orientations result in symmetric divisions in which both daughter cells receive a relatively equal complement of cytoplasmic material and consequently self-renew as clonal stem cells. Reduced angle divisions, however, are asymmetric, whereby cellular components are unevenly divided among daughter cells thus yielding one new stem cell and one differentiated progeny (Venkei and Yamashita, 2018).

The balance between symmetric self-renewing and asymmetric differentiative divisions is essential to tissue development and homeostasis, and misbalances can lead to diseases such as cytopenias or cancer. During early brain development, for example, a stem cell population expands first through symmetric divisions and subsequently through asymmetric divisions, which generate one daughter stem cell and one differentiated progeny (Julian et al., 2013; Matsuzaki and Shitamukai, 2015). In contrast, tissue homeostasis in the adult brain is maintained through a balance of symmetric selfrenewing and asymmetric neurogenic divisions (Obernier et al., 2018). Ultimately, the pattern by which cell fate determinants are distributed among daughter cells is a critical factor directing cell identity.

In addition to mitochondria, other organelles exhibit biased segregation among progeny of dividing stem cells, suggesting that they may directly impact stem cell identity determination in their own right. Unequal inheritance of ER content has been observed in asymmetrically dividing stem cell populations in a number of model systems including Drosophila melanogaster, Caenorhabditis elegans, Saccharomyces cerevisiae, the ascidian embryo, and cultured human cells (Estrada et al., 2003; Poteryaev et al., 2005; Sardet et al., 2007; Smyth et al., 2015; Eritano et al., 2017). Asymmetric distribution of the ER has also recently been observed in symmetrically expanding epithelial stem cells very early stages of Drosophila development, through a mechanism dependent on directed positioning of the ER by the highly conserved ER membrane protein Jagunal (Eritano et al., 2017).
Strikingly, this biased ER inheritance is observed immediately prior to the delamination event that precedes the transition to asymmetric neurogenic divisions and is restricted to a population of cells destined for neurogenesis. This strongly implies a direct role for the ER in stem cell fate determination; it remains to be determined, however, if asymmetric ER inheritance contributes actively to cell fate determination in mammalian systems.

Asymmetric inheritance of lysosomes and other cellular vesicles has also recently been causally linked to cell fate determination. Peroxisomes, vesicles carrying degradative enzymes involved in fatty acid and energy metabolism, have been observed in both yeast and human cells to exhibit asymmetric segregation during mitosis (Asare et al., 2017; Kumar et al., 2018). Using an unbiased RNA-sequencing and a directed RNA interference (RNAi) approach to profile epidermal stem cells and their newly differentiated progeny in developing mouse embryos, peroxisomes were shown to be critical for epidermal development through regulation of asymmetric divisions (Asare et al., 2017). These vesicles localize to spindle poles and are in fact necessary to control their alignment and the subsequent orientation of cell division relative to the stem cell niche. RNAimediated knockdown of the peroxisome membrane protein Pex11b completely disrupted epidermal development by altering cell cycle progression, symmetric and asymmetric division ratios and ultimately fate determination of the stem cell pool and the resulting tissue architecture.

Finally, in the first explicit demonstration that mammalian hematopoietic stem cells (HSCs) divide asymmetrically to control their fate, Loeffler et al. (2019) demonstrated that this asymmetry is paralleled by an uneven distribution of the cell's degradative machinery, specifically lysosomes, autophagosomes, and mitophagososmes. Preferential inheritance of these vesicles into daughter cells destined for differentiation was a defining feature dictating the identity of HSC progeny, and was linked to the regulation of mitochondrial clearance, protein translation capacity, and signaling through the Notch-Numb pathway. Thus, compelling evidence from recent discoveries implicates multiple organelles, focused heavily on cellular metabolic vesicles such as lysosomes, as active regulators of stem cell divisions that dictate cell identity decisions.

\section{LYSOSOMES AS REGULATORS OF STEM CELL IDENTITY}

Lysosomes have long been viewed as the primary effectors of the cellular waste disposal system, functioning to degrade excess or damaged organelles and macromolecules by the greater than 60 hydrolytic enzymes present within their acidic lumen (Settembre et al., 2013; Perera and Zoncu, 2016). Lysosomes are formed by the fusion of secretory vesicles from the trans Golgi network with endocytic vesicles established by plasma membrane endocytosis. Lysosomes receive and digest intracellular components including excess proteins, lipids, carbohydrates, nucleic acids, and damaged organelles by autophagosomes, and thus represent a critical end point in the autophagy system (Chang, 2020; Figure 2). Lysosomes also digest 
extracellular macromolecules and materials such as aging cells, cell debris, bacteria, and viruses delivered through endocytosis and phagocytosis.

Lysosomal degradation reduces its substrates to fundamental building blocks of macromolecules including amino acids, sugars, lipids, and nucleic acids. These metabolites are either retained in the lysosome lumen to buffer their cytoplasmic concentrations, or are actively secreted into the cytoplasm by membrane permeases where they are reused by the cell to fuel biochemical and bioenergetic pathways, or exported out of the cell (Figure 2; Sagné et al., 2001; Rong et al., 2011; Jézégou et al., 2012; Liu et al., 2012; Verdon et al., 2017; Wyant et al., 2017). It is becoming increasingly clear that the processing and transport of lysosome-generated metabolites is highly regulated, and that mechanisms permitting contact with other organelles, such as MCS interaction with mitochondria, allow for bi-directional transport of metabolites and lipids that likely fuel metabolic and other biochemical pathways. Lysosomes also function as central players in coordinating supply and demand of critical molecules involved in bioenergetic signaling (Zhang et al., 2011b; Lim and Zoncu, 2016; Savini et al., 2019; Ballabio and Bonifacino, 2020). The signaling pathways and mechanisms that impact lysosome biogenesis and function are linked to many activities that implicate them as regulators of stem cell biology, including selfrenewal and differentiation decisions, cell death, and organismal aging and longevity (Ramachandran et al., 2019; Savini et al., 2019; Ballabio and Bonifacino, 2020). An important role for lysosomes in cell identity determination is emerging, yet the mechanisms by which they may drive metabolic reprogramming and impact cell fate specification, and if these activities are indeed linked, are unclear.

\section{Metabolic Signaling Pathways Converge at the Lysosome}

Metabolic pathways and the cell biological processes with which they integrate are dynamic. Given that cells are regularly exposed to changing environmental conditions, mechanisms to finely regulate the balance between anabolic and catabolic activities are critical for cell viability, proper function, and homeostasis. This coordination is achieved by hard-wired signaling mechanisms that sense the level of available nutrients and other environmental signals like oxygen, energy status, stress markers, and growth factors, and accordingly relay downstream signals through phosphorylation events. The mammalian target of rapamycin complex 1 (mTORC1) and AMP-activated kinase (AMPK) are the primary mammalian nutrient-sensing kinases, and they function in opposition to one another to control the catabolicanabolic balance. A major breakthrough in our understanding of metabolic coordination, and one that underscored a profound physical connection between metabolic signaling and the lysosome, is that the activity status of these kinases is in fact regulated on the lysosome surface (Sancak et al., 2010; Zhang et al., 2014; Savini et al., 2019). In the decade since this discovery, we now understand that mTORC1 is in fact recruited to and activated at the lysosome in a two-step process, requiring both sufficient nutrient and growth factor signaling.
Nutrient signaling, translated through amino acid availability, activates heterodimeric Rag GTPases which physically recruit mTORC1 to the lysosome (Yang et al., 2017; Lawrence et al., 2018). Subsequently, mTORC1 interacts with the small GTPase Rheb already located on the lysosome surface. If growth factor signaling permits, the GTPase-activating protein "tuberous sclerosis complex" (TSC) will be inhibited, thus promoting activation of Rheb and consequently of mTORC1 (Tee et al., 2003; Menon et al., 2014; Savini et al., 2019).

Hyper-active mTORC1 functions at the lysosome to phosphorylate downstream targets that promote anabolic cellular processes including protein translation, ribosome and lipid biogenesis, cell growth, and mitochondrial metabolism (Delaney et al., 2014; Lawrence and Zoncu, 2019; Savini et al., 2019; Ballabio and Bonifacino, 2020). Conversely, mTORC1 inhibits catabolic activities, predominantly lysosome biogenesis, and autophagy signaling. The primary catabolic targets include the autophagosome assembly protein ULK-1 and members of the TFE transcription factor family, key factors in the activation of lysosome biogenesis genes (Sardiello et al., 2009; Palmieri et al., 2011; Settembre et al., 2011; Martina et al., 2014; Annunziata et al., 2019; Savini et al., 2019).

AMP-activated kinase is activated in response to low nutrient levels, when intracellular ATP levels are low and AMP is high, and functions to promote catabolism and inhibit anabolism largely by countering mTORC1 activities (Figure 2). mTORC1 and AMPK are regulated reciprocally by the lysosome-bound $\mathrm{v}$-ATPase that permits nutrient sensing of amino acid levels inside the lysosome in addition to cytoplasmic sensing (Zhang et al., 2014). Likewise, the cytoplasmic/lysosomal and nuclear localization of TFE transcription factors is controlled in opposing ways by mTORC1 and AMPK (Martina et al., 2012, 2014; Roczniak-Ferguson et al., 2012; Settembre et al., 2012; Young et al., 2016; Saxton and Sabatini, 2017; Napolitano et al., 2018; Asrani et al., 2019). Corroborating a coordinated mechanism that impacts the dynamics of lysosome biogenesis as well as cell fate determination, it was recently shown in the amoeba Dictyostelium that activated mTORC1 and AMPK reciprocally regulate an overlapping set of genes that dictate a fate switch between progenitor cell growth and differentiation (Jaiswal and Kimmel, 2019).

Metabolic signaling pathways centered at the lysosome are in fact important regulators of cell fate transitions. The ability to balance mTORC1 activity is critical for proper stem cell fate decisions between self-renewal and differentiation in development and aging in a number of somatic cell types, with mTORC1 hyper-activation typically driving aberrant lineage differentiation (Delaney et al., 2014; Meng et al., 2018). Loss of the TSC complex members hamartin (TSC1) or tuberin (TSC2), which drives constitutive mTORC1 activation, leads to the development of a multi-system low-grade tumor and neoplastic disorder called tuberous sclerosis. In this condition, lesions are characterized by enlarged cells expressing an atypical mixture of lineage-specific stem cell and immature differentiation markers (Delaney et al., 2014).

We and others have additionally found that the capacity to repress the mTORC1 pathway is essential for the reprogramming 
of both mouse and human somatic cells to iPSCs (He et al., 2012; Wang et al., 2013; Wu et al., 2015; Armstrong et al., 2017; Julian et al., 2017a). This requirement has been linked to both p53-dependent cell death regulation and an intriguing mechanism whereby the critical cell fate determinant SOX2 transcriptionally suppresses mTORC1, at a very early stage of iPSC reprogramming, to permit transient activation of autophagy at this critical time-point of cell fate specification (Wang et al., 2013; Armstrong et al., 2017). mTORC1 inhibition by the core pluripotency factors during early reprogramming is also required to permit the reduction in mitochondrial mass (Wang et al., 2017, 2013) that coincides with the lower OxPhos activity typical of PSCs (Folmes et al., 2011). Demonstrating that lysosomes and other organelles can affect cell identity determination in distinct ways, this mitochondrial remodeling was strikingly independent of autophagy, evidenced by findings that mitochondria-lysosome co-localization could not be observed and lysosom inhibition with bafilomycin or shRNA targeted knock-down of autophagy regulators (Atg5, Beclin or Vps34) did not affect mitochondrial mass (Wang et al., 2013). The requirement for mTORC1 inhibition in regulating pluripotency appears to be limited to the initial stage of cell identity determination, as we and others have demonstrated that the loss or reduction of TSC2, limiting the capacity to inhibit mTORC1, does not affect the maintenance of a pluripotent state in established human PSCs (Julian et al., 2017a; Blair et al., 2018; Delaney et al., 2019). Thus, mTORC1 inhibition and consequent autophagy activation appears to be critical specifically at a very early stage of cell fate transition (Figure $\mathbf{1}$ ).

\section{Emerging Evidence for Lysosomes in Lineage-Specific Fate Determination}

Though lysosome biogenesis and activity have been linked to stem cell fate decisions from development through aging, it has been unclear if lysosomes are drivers of these events or instead, passengers in the process. The acquisition and maintenance of pluripotency, for instance, requires metabolic reprogramming to a highly glycolytic state (Zhu et al., 2010; Folmes et al., 2011; Zhang et al., 2011a; Hansson et al., 2012; Panopoulos et al., 2012; Wang et al., 2013; Prigione et al., 2014) and in vitro differentiation of PSCs to downstream lineages correlates with further metabolic changes (Chung et al., 2007; TeSlaa et al., 2016; Betschinger, 2017; Cliff et al., 2017; Lees et al., 2018; Zhang et al., 2018). Our current understanding of the metabolic mechanisms driving these fate transitions is focused on the mitochondria with limited insight regarding the potential impact of other organelles. Landmark studies over the past few years have provided strong evidence that lysosomes can indeed function as drivers of both metabolic network reprogramming and stem cell fate decisions that affect cell identity determination.

It is now clear that lysosomes function as active drivers of PSC differentiation through their physical and functional interactions with the nutrient-sensing mTORC1, Rag GTPase, and AMPK complexes (Young et al., 2016; Villegas et al., 2019; Figure 2). Villegas et al. (2019) performed a genome-wide CRISPR/Cas9 screen in mouse embryonic stem cells (ESCs) under culture conditions that promoted either self-renewal or differentiation, to identify factors whose loss would impede exit from the pluripotent state. This unbiased approach identified a number of factors related to lysosome biogenesis and function as critical regulators of PSC differentiation (Villegas et al., 2019). These include genes that ensure lysosome degradative activity, as well as the Rag proteins and components of the Ragulator complex that recruits Rag proteins to the lysosome surface, necessary for control of mTORC1 activity. Also identified as a critical regulator was the tumor suppressor Folliculin, which normally translates amino acid levels to Ragulator/Rag permitting non-nuclear recruitment and sequestration of Tfe3. The authors discovered that loss of these factors leads to constitutive localization of Tfe3 in the nucleus, which is known to directly drive gene expression programs related to lysosome biogenesis and metabolic signaling. This was confirmed in the study using RNAsequencing, a strategy that revealed a secondary transcriptional response of Tfe 3 that enforces a sustained pluripotency program and represses transcriptional programs associated with periimplantation development and neural lineage differentiation.

Similarly, mouse ESCs lacking functional AMPK, which antagonizes mTORC1 activation at the lysosome and thereby inhibits its phosphorylation-induced retention of TFE proteins in the cytoplasm, exhibit profound differentiation defects. $A M P K^{-/-}$ESCs maintain pluripotency but fail to generate chimeric embryos and exhibit a preference for ectodermal compared to endodermal differentiation, due to hypophosphorylation of Tfeb and its reduced nuclear localization (Young et al., 2016). This study and others position coordinated regulation of AMPK and mTORC1 signaling to be an essential regulatory node in PSCs that determines an ectodermal or endodermal cell fate, with hyper-active mTORC1 signaling consistently leading to preferential ectodermal differentiation (Zhou et al., 2009; Young et al., 2016; Delaney et al., 2019; Jaiswal and Kimmel, 2019).

Underscoring an essential role for lysosomes in cell fate decisions particularly in NSC pools, differences in proteasome and lysosome-autophagy activity have recently been revealed as defining factors between proliferative "activated" NSC populations versus aged quiescent NSCs, whose accumulation is strongly associated with age-related cognitive decline (Leeman et al., 2018). The authors employed RNA-sequencing, again an unbiased approach, to profile transcriptional signatures of activated and quiescent cell populations within the NSC pool isolated from young and aged mice. Differences in metabolic profiles and active components of the proteostasis system, specifically the proteasome and lysosome machinery, were the most profound signatures discerning proliferative from quiescent NSCs. Transcriptional signatures and functional experiments revealed that the proteostasis machinery is highly functional in activated NSCs, whereas activity is low in quiescent cells. As quiescent NSCs age, their lysosomes become significantly enlarged and accumulate increasing amounts of insoluble aggregated proteins, which is due to a lack of efficient clearance by the lysosome. Activation of lysosome activity by TFEB expression in quiescent NSCs permitted clearance of protein aggregates and, strikingly, altered the fate of these cells to an activated state. 
Our recent work further implicates lysosome activation as a critical requirement for NSC fate regulation, in the initial determination of neural lineage identity (Delaney et al., 2019; Figure 1). We developed a modeling system of the multi-system tumor disorder tuberous sclerosis by engineering inactivating TSC2 mutations in human PSCs, thereby inducing mTORC1 hyperactivation, and subsequently differentiating them in a directed manner into NSCs and the developmentally related neural crest (NC). These two lineages are the presumed derivative cell types of the diverse lesions and tumors in tuberous sclerosis patients (Delaney et al., 2014). Seeking to determine the mechanisms by which normal (WT) and TSC2 ${ }^{-/-}$ PSCs commit to an NSC or NC fate, we employed RNAsequencing and functional analysis approaches to identify the primary biological processes at play during the transition from pluripotency to the new cellular identity. An increase in lysosome content, driven by an acute activation of a proteostasis stress response, was evident at very early stages of PSCNSC induction, but not during NC specification. This was observed in WT cells and was further exacerbated in cells lacking TSC2. Of note, a recent study revealed that cells undergoing NSC specification undergo a reprogramming of protein chaperone networks, which are intimately connected with proteostatic mechanisms; this finding underscores the importance of proteostasis signaling integrity during early NSC development (Vonk et al., 2020). Furthermore, lysosome content changed dynamically throughout NSC induction in TSC2-/cells, and these patterns correlated with alterations in the expression of cell fate markers (Delaney et al., 2019).

The aberrant lysosome activation driven by TSC2-deficiency was transient during neural development but became reactivated with time as NSC cultures were aged, in a manner that paralleled altered expression of cell fate markers (Delaney et al., 2019). These findings suggest a close association of lysosome biogenesis with cell fate in NSC populations, both during their initial specification and long-term maintenance. Our findings that early induced NSCs lacking TSC2 activate lysosome biogenesis, while maintaining degradative activity through autophagy, in parallel with hyperactive mTORC1 signaling reveals the existence of early adaptive mechanisms in metabolic circuits to ensure proper signaling for lineage development. A recent study suggests that autophagy-dependent lipid metabolism is an important aspect of these adaptations (Wang et al., 2019). We also found that increased lysosome biogenesis preceded later changes in mitochondrial content, which correlated with aberrant activation of oxidative metabolism uniquely in TSC2 $2^{-/-}$NSCs (Delaney et al., 2019). This demonstrates that lysosome activation can be a driver of metabolic and cell fate changes, at least in the neural lineage, and is not simply a downstream consequence of mitochondrial alterations (Figure 1).

\section{Implications for Disease Mechanisms and Treatment}

Many human disorders, ranging from developmental to aginginduced conditions and various forms of cancer, exhibit aberrant lysosome activity as a known or predicted factor contributing to pathogenic phenotypes. The over 50 rare genetic metabolic conditions under the umbrella of "lysosomal storage diseases" typically present early in life, yet we now know that they share many clinical, pathological and genetic features with age-related neurological conditions, including frontotemporal dementia, Alzheimer's and Parkinson's disease (Fraldi et al., 2016). Shared pathological phenotypes are typified by metabolic dysfunction and an accumulation of aggregated proteins as a consequence of insufficient proteostasis mechanisms that include altered lysosome activity. Retrospective studies and PSC-based disease modeling approaches, which permit detailed analysis of the biological effects of allele variants starting from the earliest stages of cell lineage development, have begun to reveal that gene mutations associated with adult onset degenerative conditions can confer measurable phenotypes during development or at much earlier stages than previously considered (Delaney et al., 2019; Smits et al., 2019; Zhu et al., 2019; Johnson et al., 2020). Examples include altered stem cell proliferation, differentiation decisions, metabolic and proteostasis signaling in studies of tuberous sclerosis, Alzheimer's and Parkinson's disease (Delaney et al., 2019; Smits et al., 2019; Zhu et al., 2019). Lysosomal dysfunction and metabolic reprogramming have also been implicated in neurological conditions not directly associated with degeneration, including psychiatric and seizure disorders; likewise, many lysosomal storage diseases and other conditions, such as inherited tumor syndromes, present with psychiatric disease and often neurodegeneration (Staretz-Chacham et al., 2010; Marques and Saftig, 2019).

It is therefore clear that the brain, and the neural cell lineage that builds this organ, are highly dependent on the lysosome for proteostasis regulation and is particularly sensitive to developing disease when faced with lysosome dysfunction. This neural lineage proteostasis sensitivity is often attributed to the fact that neurons are highly active biologically but unable to divide and thereby have no progeny through which to dilute protein aggregates and aberrant regulatory machinery. Our recent work and that of others discussed in this review (Zhou et al., 2009; Young et al., 2016; Leeman et al., 2018; Delaney et al., 2019; Jaiswal and Kimmel, 2019) suggest that unique proteostatic mechanisms with a particular dependency on lysosome-mediated degradation are in fact active at the earliest stages of neural lineage development. Moreover, these findings imply that lysosome activation is critical for NSC fate determination, suggesting a hard-wired integration of lysosomal signaling mechanisms with metabolic and transcriptional programs that coordinate NSC identity.

Hard-wiring of lysosomal signaling in NSCs has implications for understanding susceptibility to neurological disease, as well as the stage-specific drivers of diseases that are associated with changes in markers of cell fate and identity, such as cancer (Figure 1). Similar to stem cells transitioning between cell fates, tumorigenesis is associated with dramatic metabolic alterations. These are typically unique to each tumor type but are common conceptually, given that significant metabolic remodeling occurs at each phase from pre-malignant lesion, to aggressive primary tumor, and consequently metastasis (Faubert et al., 2020). These changes occur as tumors, typically thought to be driven by 
populations of adaptive CSCs, face ever changing environments that are commonly low in oxygen and standard energy sources (Nazio et al., 2019).

Many new and developing therapeutic strategies for cancer are directed toward targeting metabolic vulnerabilities of the tumor. Inhibition of lysosome activity by targeting autophagy signaling, using lysosomotropic agents like bafilomycin or chloroquine derivatives, or degradative capacity and ion transport are popular among these approaches (Nazio et al., 2019; Méndez-Lucas et al., 2020). Yet, despite the clear vulnerability of metabolic and lysosome-based networks in cancer, current lysosometargeted drugs have had limited success in clinical trials, often failing to provide adequate tumor-specific toxicity at least as single agents. We posit that a deeper understanding of the organelle-based processes that drive CSC adaptations is one avenue that will lead to more targeted selection of therapeutic agents based on the tumorigenic stage, the lineage identity of resident CSCs, and the driving biological mechanisms (Figure 1).

Efforts aimed at elucidating the extent to which lysosome dynamics influence cell fate specification in stem cell populations are likely to yield important therapeutic insights. Using CSCs as an example, an important approach is to discern whether altered lysosome signaling in a given tumor type is an early precipitating event in cell fate and metabolic dysfunction, as we observed in our human stem cell model of tuberous sclerosis (Delaney et al., 2019), or instead a secondary event, potentially consequent to mitochondrial reprogramming. An improved understanding of the driving and secondary adaptive mechanisms that contribute to stem cell-based disease has high potential to reveal effective stage-specific biomarkers and to guide rational development of therapeutic strategies.

Lysosomes are complex organelles, with an ever-growing list of associated biological functions with the potential to impact stem cell fate and identity determination (Figure 2). Beyond their canonical role of degrading macromolecules through their acidic environment and portfolio of hydrolytic enzymes, they also act as nutrient sensors, platforms for signaling pathways, regulators of lipid production and transport, and mediators of ion, nucleic acid, amino acid, and metabolite signaling and transport. Lysosomes are also structurally dynamic, undergoing fission and fusion events, relying on their connection to the actin cytoskeleton, and can physically and functionally interact with multiple organelles. Additionally, they have emerged as regulators of transcriptional programs, for instance by modulating TFE sub-cellular localization and engaging lipid metabolites for nuclear signaling.

It is likely that many more functions remain to be uncovered by which the lysosome impacts stem cell fate. For instance, mTORC1 and AMPK are not the only signaling hubs located at the lysosome surface; additionally, there are likely many more mechanisms to be uncovered that contribute to mTORC1dependent molecular sensing (Young et al., 2016; Savini et al., 2019; Ballabio and Bonifacino, 2020). Moving forward it will be critical to understand the mechanisms by which lysosomes impact cell fate specification, especially their impacts on transcriptional and translational programs. For example, are there additional mechanisms outside of lipid and TFE signaling by which the lysosome affects transcriptional programs? Possibilities include direct regulation of the expression or localization of additional transcription factors, or the production and transport of metabolites that affect epigenetic signatures. Lysosome metabolite profiling represents a particularly exciting and newly developing area of research that will undoubtedly help deepen our understanding of the mechanisms by which this organelle impacts stem cell identity determination, and furthermore how it may be efficiently targeted in cancer and disease states (Abu-Remaileh et al., 2017). Acquiring a deeper understanding of lysosome-based signaling at the metabolite level and beyond has the potential to discover targeted biomarkers and therapeutic approaches for stem cell-based disease, and to improve strategies for tissue regeneration.

\section{CONCLUDING REMARKS}

Regulation of stem cell fate decisions is heavily predicated on the integration of transcriptional and metabolic signaling networks. Our understanding of the metabolic impacts on cell fate have been largely limited to the mitochondria, yet it is becoming increasingly evident that multiple organelles interact with one another in diverse ways to regulate cell fate. The lysosome is now well appreciated as not only the waste disposal center of the cell but as an active and multifunctional player in coordinating metabolic networks; exciting work over the past few years has provided compelling evidence that lysosome-based activities are in fact crucial for regulating cell identity determination and other fate decisions. The lysosome is a multi-functional organelle whose activities and regulatory partners are still being uncovered. Thus, focusing efforts on unraveling the biological impacts of lysosome signaling on cell fate regulation has high potential to significantly impact our understanding of tissue development and aging, disease predisposition and pathogenesis, as well as disease treatment and regenerative medicine strategies.

\section{AUTHOR CONTRIBUTIONS}

LJ wrote the manuscript and prepared the figures. WS reviewed and edited the manuscript, provided intellectual insights, and acquired funds for publication. Both authors contributed to the article and approved the submitted version.

\section{FUNDING}

Figures were created with BioRender.com. Our own lysosome and mTORC1 research has been supported by grants to WS from the Canadian Institutes for Health Research (CIHR; FRN153188) and the Tuberous Sclerosis Complex Research Program of the Congressionally Directed Medical Research Program (W81XWH-14-1-043). LJ is supported by the Cancer Research Society Scholarships for the Next Generation of Scientists and WS is supported by the Canada Research Chair Program. 


\section{REFERENCES}

Abdolhosseini, F., Azarkhalili, B., Maazallahi, A., Kamal, A., Motahari, S. A., Sharifi-Zarchi, A., et al. (2019). Cell identity codes: understanding cell identity from gene expression profiles using deep neural networks. Sci. Rep. 9:2342. doi: 10.1038/s41598-019-38798-y

Abu-Remaileh, M., Wyant, G. A., Kim, C., Laqtom, N. N., Abbasi, M., Chan, S. H., et al. (2017). Lysosomal metabolomics reveals V-ATPase- and mTORdependent regulation of amino acid efflux from lysosomes. Science 358, $807-$ 813. doi: $10.1126 /$ science.aan6298

Annunziata, I., van de Vlekkert, D., Wolf, E., Finkelstein, D., Neale, G., Machado, E., et al. (2019). MYC competes with MiT/TFE in regulating lysosomal biogenesis and autophagy through an epigenetic rheostat. Nat. Commun. 10:3623.

Armstrong, L. C., Westlake, G., Snow, J. P., Cawthon, B., Armour, E., Bowman, A. B., et al. (2017). Heterozygous loss of TSC2 alters p53 signaling and human stem cell reprogramming. Hum. Mol. Genet. 26, 4629-4641. doi: 10.1093/hmg/ ddx345

Asare, A., Levorse, J., and Fuchs, E. (2017). Coupling organelle inheritance with mitosis to balance growth and differentiation. Science 355:eaah4701. doi: 10 . 1126/science.aah4701

Asrani, K., Murali, S., Lam, B., Na, C.-H., Phatak, P., Sood, A., et al. (2019). mTORC1 feedback to AKT modulates lysosomal biogenesis through MiT/TFE regulation. J. Clin. Invest. 129, 5584-5599. doi: 10.1172/JCI128287

Bahat, A., and Gross, A. (2019). Mitochondrial plasticity in cell fate regulation. J. Biol. Chem. 294, 13852-13863. doi: 10.1074/jbc.REV118.000828

Baker, N., Patel, J., and Khacho, M. (2019). Linking mitochondrial dynamics, cristae remodeling and supercomplex formation: how mitochondrial structure can regulate bioenergetics. Mitochondrion 49, 259-268. doi: 10.1016/j.mito. 2019.06.003

Ballabio, A., and Bonifacino, J. S. (2020). Lysosomes as dynamic regulators of cell and organismal homeostasis. Nat. Rev. Mol. Cell Biol. 21, 101-118. doi 10.1038/s41580-019-0185-4

Bankaitis, V. A., and Xie, Z. (2019). The neural stem cell/carnitine malnutrition hypothesis: new prospects for effective reduction of autism risk? J. Biol. Chem. 294, 19424-19435. doi: 10.1074/jbc.AW119.008137

Betschinger, J. (2017). Charting developmental dissolution of pluripotency. J. Mol. Biol. 429, 1441-1458. doi: 10.1016/j.jmb.2016.12.017

Blair, J. D., Hockemeyer, D., and Bateup, H. S. (2018). Genetically engineered human cortical spheroid models of tuberous sclerosis. Nat. Med. 277, 805-808. doi: 10.1038/s41591-018-0139-y

Böckler, S., Chelius, X., Hock, N., Klecker, T., Wolter, M., Weiss, M., et al. (2017). Fusion, fission, and transport control asymmetric inheritance of mitochondria and protein aggregates. J. Cell Biol. 216, 2481-2498. doi: 10.1083/jcb.201 611197

Cantó, C., Menzies, K. J., and Auwerx, J. (2015). NAD(+) metabolism and the control of energy homeostasis: a balancing act between mitochondria and the nucleus. Cell Metab. 22, 31-53. doi: 10.1016/j.cmet.2015.05.023

Carey, B. W., Finley, L. W. S., Cross, J. R., Allis, C. D., and Thompson, C. B. (2015). Intracellular $\alpha$-ketoglutarate maintains the pluripotency of embryonic stem cells. Nature 518, 413-416. doi: 10.1038/nature13981

Chang, N. C. (2020). Autophagy and stem cells: self-eating for self-renewal. Front. Cell. Dev. Biol. 8:138. doi: 10.3389/fcell.2020.00138

Chang, N. C., Sincennes, M.-C., Chevalier, F. P., Brun, C. E., Lacaria, M., Segalés, J., et al. (2018). The dystrophin glycoprotein complex regulates the epigenetic activation of muscle stem cell commitment. Cell Stem Cell 22, 755-768.e6. doi: 10.1016/j.stem.2018.03.022

Chen, Y.-G., Ezhkova, E., and Ostankovitch, M. (2016). Molecular mechanisms regulating stem cells fate. J. Mol. Biol. 428, 1407-1408. doi: 10.1016/j.jmb.2016. 03.011

Chung, S., Dzeja, P. P., Faustino, R. S., Perez-Terzic, C., Behfar, A., and Terzic, A. (2007). Mitochondrial oxidative metabolism is required for the cardiac differentiation of stem cells. Nat. Clin. Pract. Cardiovasc. Med. 4(Suppl. 1), S60-S67. doi: 10.1038/ncpcardio0766

Cliff, T. S., Wu, T., Boward, B. R., Yin, A., Yin, H., Glushka, J. N., et al. (2017). MYC controls human pluripotent stem cell fate decisions through regulation of metabolic flux. Cell Stem Cell 21, 502-516.e9. doi: 10.1016/j.stem.2017. 08.018
Copeland, D. E., and Dalton, A. J. (1959). An association between mitochondria and the endoplasmic reticulum in cells of the pseudobranch gland of a teleost. J. Biophys. Biochem. Cytol. 5, 393-396. doi: 10.1083/jcb.5.3.393

Dalton, C. M., and Carroll, J. (2013). Biased inheritance of mitochondria during asymmetric cell division in the mouse oocyte. J. Cell Sci. 126, 2955-2964. doi: $10.1242 /$ jcs. 128744

Delaney, S. P., Julian, L. M., Pietrobon, A., Yockell-Lelièvre, J., Doré, C., Wang, T. T., et al. (2019). Stem cell models identify lineage-specific catabolic signaling, neoplastic mechanisms and therapeutic vulnerabilities in tuberous sclerosis. bioRxiv [Preprint] doi: 10.1101/683359

Delaney, S. P., Julian, L. M., and Stanford, W. L. (2014). The neural crest lineage as a driver of disease heterogeneity in Tuberous Sclerosis Complex and lymphangioleiomyomatosis. Front. Cell. Dev. Biol. 2:69. doi: 10.3389/fcell.2014. 00069

Eritano, A. S., Altamirano, A., Beyeler, S., Gaytan, N., Velasquez, M., and Riggs, B. (2017). The endoplasmic reticulum is partitioned asymmetrically during mitosis before cell fate selection in proneuronal cells in the early Drosophila embryo. Mol. Biol. Cell 28, 1530-1538. doi: 10.1091/mbc.e16-09-0690

Estrada, P., Kim, J., Coleman, J., Walker, L., Dunn, B., Takizawa, P., et al. (2003). Myo4p and She3p are required for cortical ER inheritance in Saccharomyces cerevisiae. J. Cell Biol. 163, 1255-1266. doi: 10.1083/jcb.200304030

Faubert, B., Solmonson, A., and DeBerardinis, R. J. (2020). Metabolic reprogramming and cancer progression. Science 368:eaaw5473. doi: 10.1126/ science.aaw5473

Folick, A., Oakley, H. D., Yu, Y., Armstrong, E. H., Kumari, M., Sanor, L., et al. (2015). Aging. Lysosomal signaling molecules regulate longevity in Caenorhabditis elegans. Science 347, 83-86. doi: 10.1126/science.1258857

Folmes, C. D. L., Dzeja, P. P., Nelson, T. J., and Terzic, A. (2012). Metabolic plasticity in stem cell homeostasis and differentiation. Cell Stem Cell 11, 596606. doi: 10.1016/j.stem.2012.10.002

Folmes, C. D. L., Nelson, T. J., Martinez-Fernandez, A., Arrell, D. K., Lindor, J. Z., Dzeja, P. P., et al. (2011). Somatic oxidative bioenergetics transitions into pluripotency-dependent glycolysis to facilitate nuclear reprogramming. Cell Metab. 14, 264-271. doi: 10.1016/j.cmet.2011.06.011

Fraldi, A., Klein, A. D., Medina, D. L., and Settembre, C. (2016). Brain disorders due to lysosomal dysfunction. Annu. Rev. Neurosci. 39, 277-295. doi: 10.1146/ annurev-neuro-070815-014031

Friedman, J. R., Dibenedetto, J. R., West, M., Rowland, A. A., and Voeltz, G. K. (2013). Endoplasmic reticulum-endosome contact increases as endosomes traffic and mature. Mol. Biol. Cell 24, 1030-1040. doi: 10.1091/mbc.e12-100733

Fu, J., Gaetani, S., Oveisi, F., Lo Verme, J., Serrano, A., Rodriguez De Fonseca, F., et al. (2003). Oleylethanolamide regulates feeding and body weight through activation of the nuclear receptor PPAR-alpha. Nature 425, 90-93. doi: 10.1038/ nature 01921

Gordaliza-Alaguero, I., Cantó, C., and Zorzano, A. (2019). Metabolic implications of organelle-mitochondria communication. EMBO Rep. 20:e47928. doi: 10. 15252/embr.201947928

Guha, M., and Avadhani, N. G. (2013). Mitochondrial retrograde signaling at the crossroads of tumor bioenergetics, genetics and epigenetics. Mitochondrion 13, 577-591. doi: 10.1016/j.mito.2013.08.007

Göbel, J., Engelhardt, E., Pelzer, P., Sakthivelu, V., Jahn, H. M., Jevtic, M., et al. (2020). Mitochondria-endoplasmic reticulum contacts in reactive astrocytes promote vascular remodeling. Cell Metab. 31, 791-808.e8. doi: 10.1016/j.cmet. 2020.03.005

Hansson, J., Rafiee, M. R., Reiland, S., Polo, J. M., Gehring, J., Okawa, S., et al. (2012). Highly coordinated proteome dynamics during reprogramming of somatic cells to pluripotency. Cell Rep. 2, 1579-1592. doi: 10.1016/j.celrep.2012. 10.014

Hao, F., Kondo, K., Itoh, T., Ikari, S., Nada, S., Okada, M., et al. (2018). Rheb localized on the Golgi membrane activates lysosome-localized mTORC1 at the Golgi-lysosome contact site. J. Cell Sci. 131:jcs208017. doi: 10.1242/jcs.208017

Harvey, A., Caretti, G., Moresi, V., Renzini, A., and Adamo, S. (2019). Interplay between metabolites and the epigenome in regulating embryonic and adult stem cell potency and maintenance. Stem Cell Rep. 13, 573-589. doi: 10.1016/j. stemcr.2019.09.003

He, J., Kang, L., Wu, T., Zhang, J., Wang, H., Gao, H., et al. (2012). An elaborate regulation of mammalian target of rapamycin activity is required for somatic 
cell reprogramming induced by defined transcription factors. Stem Cells Dev. 21, 2630-2641. doi: 10.1089/scd.2012.0015

Hönscher, C., Mari, M., Auffarth, K., Bohnert, M., Griffith, J., Geerts, W., et al. (2014). Cellular metabolism regulates contact sites between vacuoles and mitochondria. Dev. Cell 30, 86-94. doi: 10.1016/j.devcel.2014.06.006

Intlekofer, A. M., and Finley, L. W. S. (2019). Metabolic signatures of cancer cells and stem cells. Nat. Metab. 1, 177-188. doi: 10.1038/s42255-019-0032-0

Jaiswal, P., and Kimmel, A. R. (2019). mTORC1/AMPK responses define a core gene set for developmental cell fate switching. BMC Biol. 17:58. doi: 10.1186/ s12915-019-0673-1

Jézégou, A., Llinares, E., Anne, C., Kieffer-Jaquinod, S., O’Regan, S., Aupetit, J., et al. (2012). Heptahelical protein PQLC2 is a lysosomal cationic amino acid exporter underlying the action of cysteamine in cystinosis therapy. Proc. Natl. Acad. Sci. U.S.A. 109, E3434-E3443. doi: 10.1073/pnas.1211 198109

Johnson, E. C. B., Dammer, E. B., Duong, D. M., Ping, L., Zhou, M., Yin, L., et al. (2020). Large-scale proteomic analysis of Alzheimer's disease brain and cerebrospinal fluid reveals early changes in energy metabolism associated with microglia and astrocyte activation. Nat. Med. 26, 769-780. doi: 10.1038/s41591020-0815-6

Julian, L. M., and Blais, A. (2015). Transcriptional control of stem cell fate by E2Fs and pocket proteins. Front. Genet. 6:161. doi: 10.3389/fgene.2015.00161

Julian, L. M., Delaney, S. P., Wang, Y., Goldberg, A. A., Doré, C., Yockell-Lelièvre, J., et al. (2017a). Human pluripotent stem cell-derived TSC2-haploinsufficient smooth muscle cells recapitulate features of lymphangioleiomyomatosis. Cancer Res. 77, 5491-5502. doi: 10.1158/0008-5472.can-17-0925

Julian, L. M., McDonald, A. C., and Stanford, W. L. (2017b). Direct reprogramming with SOX factors: masters of cell fate. Curr. Opin. Genet. Dev. 46, 24-36. doi: 10.1016/j.gde.2017.06.005

Julian, L. M., Vandenbosch, R., Pakenham, C. A., Andrusiak, M. G., Nguyen, A. P., McClellan, K. A., et al. (2013). Opposing regulation of Sox2 by cellcycle effectors E2f3a and E2f3b in neural stem cells. Cell Stem Cell 12, 440-452. doi: 10.1016/j.stem.2013.02.001

Katajisto, P., Döhla, J., Chaffer, C. L., Pentinmikko, N., Marjanovic, N., Iqbal, S., et al. (2015). Stem cells. Asymmetric apportioning of aged mitochondria between daughter cells is required for stemness. Science 348, 340-343. doi: $10.1126 /$ science. 1260384

Khacho, M., Clark, A., Svoboda, D. S., Azzi, J., MacLaurin, J. G., Meghaizel, C., et al. (2016). Mitochondrial dynamics impacts stem cell identity and fate decisions by regulating a nuclear transcriptional program. Cell Stem Cell 19, 232-247. doi: $10.1016 /$ j.stem.2016.04.015

Khacho, M., Clark, A., Svoboda, D. S., MacLaurin, J. G., Lagace, D. C., Park, D. S., et al. (2017). Mitochondrial dysfunction underlies cognitive defects as a result of neural stem cell depletion and impaired neurogenesis. Hum. Mol. Genet. 26, 3327-3341. doi: 10.1093/hmg/ddx217

Khacho, M., Harris, R., and Slack, R. S. (2019). Mitochondria as central regulators of neural stem cell fate and cognitive function. Nat. Rev. Neurosci. 20, 34-48. doi: 10.1038/s41583-018-0091-3

Khacho, M., and Slack, R. S. (2017a). Mitochondrial activity in the regulation of stem cell self-renewal and differentiation. Curr. Opin. Cell Biol. 49, 1-8. doi: 10.1016/j.ceb.2017.11.003

Khacho, M., and Slack, R. S. (2017b). Mitochondrial and reactive oxygen species signaling coordinate stem cell fate decisions and life long maintenance. Antioxid. Redox Signal. 28, 1090-1101. doi: 10.1089/ars.2017.7228

Kinney, M. A., Vo, L. T., Frame, J. M., Barragan, J., Conway, A. J., Li, S., et al. (2019). A systems biology pipeline identifies regulatory networks for stem cell engineering. Nat. Biotechnol. 37, 810-818. doi: 10.1038/s41587-019-0159-2

Knobloch, M., Pilz, G.-A., Ghesquière, B., Kovacs, W. J., Wegleiter, T., Moore, D. L., et al. (2017). A fatty acid oxidation-dependent metabolic shift regulates adult neural stem cell activity. Cell Rep. 20, 2144-2155. doi: 10.1016/j.celrep.2017. 08.029

Kumar, S., de Boer, R., and van der Klei, I. J. (2018). Yeast cells contain a heterogeneous population of peroxisomes that segregate asymmetrically during cell division. J. Cell Sci. 131:jcs207522. doi: 10.1242/jcs.207522

Lawrence, R. E., Cho, K. F., Rappold, R., Thrun, A., Tofaute, M., Kim, D. J., et al. (2018). A nutrient-induced affinity switch controls mTORC1 activation by its Rag GTPase-ragulator lysosomal scaffold. Nat. Cell Biol. 20, 1052-1063. doi: 10.1038/s41556-018-0148-6
Lawrence, R. E., and Zoncu, R. (2019). The lysosome as a cellular centre for signalling, metabolism and quality control. Nat. Cell Biol. 21, 133-142. doi: 10.1038/s41556-018-0244-7

Leeman, D. S., Hebestreit, K., Ruetz, T., Webb, A. E., McKay, A., Pollina, E. A., et al. (2018). Lysosome activation clears aggregates and enhances quiescent neural stem cell activation during aging. Science 359, 1277-1283. doi: 10.1126/science. aag3048

Lees, J. G., Gardner, D. K., and Harvey, A. J. (2018). Mitochondrial and glycolytic remodeling during nascent neural differentiation of human pluripotent stem cells. Development 145:dev168997. doi: 10.1242/dev.168997

Lim, C.-Y., and Zoncu, R. (2016). The lysosome as a command-and-control center for cellular metabolism. J. Cell Biol. 214, 653-664. doi: 10.1083/jcb.201607005

Liu, B., Du, H., Rutkowski, R., Gartner, A., and Wang, X. (2012). LAAT-1 is the lysosomal lysine/arginine transporter that maintains amino acid homeostasis. Science 337, 351-354. doi: 10.1126/science.1220281

Loeffler, D., Wehling, A., Schneiter, F., Zhang, Y., Müller-Bötticher, N., Hoppe, P. S., et al. (2019). Asymmetric lysosome inheritance predicts activation of haematopoietic stem cells. Nature 573, 426-429. doi: 10.1038/s41586-0191531-6

Marques, A. R. A., and Saftig, P. (2019). Lysosomal storage disorders challenges, concepts and avenues for therapy: beyond rare diseases. J. Cell Sci. 132:jcs221739. doi: $10.1242 /$ jcs.221739

Martina, J. A., Chen, Y., Gucek, M., and Puertollano, R. (2012). MTORC1 functions as a transcriptional regulator of autophagy by preventing nuclear transport of TFEB. Autophagy 8, 903-914. doi: 10.4161/auto. 19653

Martina, J. A., Diab, H. I., Lishu, L., Jeong-A, L., Patange, S., Raben, N., et al. (2014). The nutrient-responsive transcription factor TFE3 promotes autophagy, lysosomal biogenesis, and clearance of cellular debris. Sci. Signal. 7:ra9. doi: 10.1126/scisignal.2004754

Matsuzaki, F., and Shitamukai, A. (2015). Cell division modes and cleavage planes of neural progenitors during mammalian cortical development. Cold Spring Harb. Perspect. Biol. 7:a015719. doi: 10.1101/cshperspect.a015719

Méndez-Lucas, A., Lin, W., Driscoll, P. C., Legrave, N., Vilaseca, L. N., Xie, C., et al. (2020). Identifying strategies to target the metabolic flexibility of tumours. bioRxiv [Preprint] doi: 10.1101/2020.01.06.896571

Meng, D., Frank, A. R., and Jewell, J. L. (2018). mTOR signaling in stem and progenitor cells. Development 145:dev152595. doi: 10.1242/dev.152595

Menon, S., Dibble, C. C., Talbott, G., Hoxhaj, G., Valvezan, A. J., Takahashi, H., et al. (2014). Spatial control of the TSC complex integrates insulin and nutrient regulation of mTORC1 at the lysosome. Cell 156, 771-785. doi: 10.1016/j.cell. 2013.11.049

Napolitano, G., Esposito, A., Choi, H., Matarese, M., Benedetti, V., Di Malta, C., et al. (2018). mTOR-dependent phosphorylation controls TFEB nuclear export. Nat. Commun. 9:3312.

Nazio, F., Bordi, M., Cianfanelli, V., Locatelli, F., and Cecconi, F. (2019). Autophagy and cancer stem cells: molecular mechanisms and therapeutic applications. Cell Death Differ. 26, 690-702. doi: 10.1038/s41418-019-0292-y

Obernier, K., Cebrian-Silla, A., Thomson, M., Parraguez, J. I., Anderson, R., Guinto, C., et al. (2018). Adult neurogenesis is sustained by symmetric selfrenewal and differentiation. Cell Stem Cell 22, 221-234.e8. doi: 10.1016/j.stem. 2018.01.003

Palmieri, M., Impey, S., Kang, H., di Ronza, A., Pelz, C., Sardiello, M., et al. (2011). Characterization of the CLEAR network reveals an integrated control of cellular clearance pathways. Hum. Mol. Genet. 20, 3852-3866. doi: 10.1093/ $\mathrm{hmg} / \mathrm{ddr} 306$

Panopoulos, A. D., Yanes, O., Ruiz, S., Kida, Y. S., Diep, D., Tautenhahn, R., et al. (2012). The metabolome of induced pluripotent stem cells reveals metabolic changes occurring in somatic cell reprogramming. Cell Res. 22, 168-177. doi: 10.1038/cr.2011.177

Perera, R. M., and Zoncu, R. (2016). The lysosome as a regulatory hub. Annu. Rev. Cell Dev. Biol. 32, 223-253. doi: 10.1146/annurev-cellbio-111315-125125

Pinto, J. P., Machado, R. S. R., Magno, R., Oliveira, D. V., Machado, S., Andrade, R. P., et al. (2018). StemMapper: a curated gene expression database for stem cell lineage analysis. Nucleic Acids Res. 46, D788-D793. doi: 10.1093/nar/gkx921

Poteryaev, D., Squirrell, J. M., Campbell, J. M., White, J. G., and Spang, A. (2005). Involvement of the actin cytoskeleton and homotypic membrane fusion in ER dynamics in Caenorhabditis elegans. Mol. Biol. Cell 16, 2139-2153. doi: 10.1091/mbc.e04-08-0726 
Prigione, A., Rohwer, N., Hoffmann, S., Mlody, B., Drews, K., Bukowiecki, R., et al. (2014). HIF1 $\alpha$ modulates cell fate reprogramming through early glycolytic shift and upregulation of PDK1-3 and PKM2. Stem Cells 32, 364-376. doi: 10.1002/stem.1552

Ramachandran, P. V., Savini, M., Folick, A. K., Hu, K., Masand, R., Graham, B. H., et al. (2019). Lysosomal signaling promotes longevity by adjusting mitochondrial activity. Dev. Cell 48, 685-696.e5. doi: 10.1016/j.devcel.2018.12. 022

Roczniak-Ferguson, A., Petit, C. S., Froehlich, F., Qian, S., Ky, J., Angarola, B., et al. (2012). The transcription factor TFEB links mTORC1 signaling to transcriptional control of lysosome homeostasis. Sci. Signal. 5:ra42. doi: 10. 1126/scisignal.2002790

Rong, Y., McPhee, C. K., McPhee, C., Deng, S., Huang, L., Chen, L., et al. (2011). Spinster is required for autophagic lysosome reformation and mTOR reactivation following starvation. Proc. Natl. Acad. Sci. U.S.A. 108, 7826-7831. doi: $10.1073 /$ pnas. 1013800108

Saffi, G. T., and Botelho, R. J. (2019). Lysosome fission: planning for an exit. Trends Cell Biol. 29, 635-646. doi: 10.1016/j.tcb.2019.05.003

Sagné, C., Agulhon, C., Ravassard, P., Darmon, M., Hamon, M., El Mestikawy, S., et al. (2001). Identification and characterization of a lysosomal transporter for small neutral amino acids. Proc. Natl. Acad. Sci. U.S.A. 98, 7206-7211. doi: 10.1073/pnas.121183498

Sancak, Y., Bar-Peled, L., Zoncu, R., Markhard, A. L., Nada, S., and Sabatini, D. M. (2010). Ragulator-rag complex targets mTORC1 to the lysosomal surface and is necessary for its activation by amino acids. Cell 141, 290-303. doi: 10.1016/j. cell.2010.02.024

Sardet, C., Paix, A., Prodon, F., Dru, P., and Chenevert, J. (2007). From oocyte to 16-cell stage: cytoplasmic and cortical reorganizations that pattern the ascidian embryo. Dev. Dyn. 236, 1716-1731. doi: 10.1002/dvdy.21136

Sardiello, M., Palmieri, M., di Ronza, A., Medina, D. L., Valenza, M., Gennarino, V. A., et al. (2009). A gene network regulating lysosomal biogenesis and function. Science 325, 473-477. doi: 10.1126/science.1174447

Savini, M., Zhao, Q., and Wang, M. C. (2019). Lysosomes: signaling hubs for metabolic sensing and longevity. Trends Cell Biol. 29, 876-887. doi: 10.1016/ j.tcb.2019.08.008

Saxton, R. A., and Sabatini, D. M. (2017). mTOR signaling in growth, metabolism, and disease. Cell 168, 960-976. doi: 10.1016/j.cell.2017.02.004

Schrader, M., Godinho, L. F., Costello, J. L., and Islinger, M. (2015). The different facets of organelle interplay-an overview of organelle interactions. Front. Cell. Dev. Biol. 3:56. doi: 10.3389/fcell.2015.00056

Sebastián, D., Hernández-Alvarez, M. I., Segalés, J., Sorianello, E., Muñoz, J. P., Sala, D., et al. (2012). Mitofusin 2 (Mfn2) links mitochondrial and endoplasmic reticulum function with insulin signaling and is essential for normal glucose homeostasis. Proc. Natl. Acad. Sci. U.S.A. 109, 5523-5528. doi: 10.1073/pnas. 1108220109

Sebastián, D., Sorianello, E., Segalés, J., Irazoki, A., Ruiz-Bonilla, V., Sala, D., et al. (2016). Mfn2 deficiency links age-related sarcopenia and impaired autophagy to activation of an adaptive mitophagy pathway. EMBO J. 35, 1677-1693. doi: 10.15252/embj.201593084

Settembre, C., Di Malta, C., Polito, V. A., Garcia Arencibia, M., Vetrini, F., Erdin, S., et al. (2011). TFEB links autophagy to lysosomal biogenesis. Science 332, 1429-1433. doi: 10.1126/science.1204592

Settembre, C., Fraldi, A., Medina, D. L., and Ballabio, A. (2013). Signals from the lysosome: a control centre for cellular clearance and energy metabolism. Nat. Rev. Mol. Cell Biol. 14, 283-296. doi: 10.1038/nrm3565

Settembre, C., Zoncu, R., Medina, D. L., Vetrini, F., Erdin, S., Erdin, S., et al. (2012). A lysosome-to-nucleus signalling mechanism senses and regulates the lysosome via mTOR and TFEB. EMBO J. 31, 1095-1108. doi: 10.1038/emboj. 2012.32

Shah, N. M., Groves, A. K., and Anderson, D. J. (1996). Alternative neural crest cell fates are instructively promoted by TGFbeta superfamily members. Cell 85 , 331-343. doi: 10.1016/s0092-8674(00)81112-5

Sheftel, A. D., Zhang, A.-S., Brown, C., Shirihai, O. S., and Ponka, P. (2007). Direct interorganellar transfer of iron from endosome to mitochondrion. Blood 110, 125-132. doi: 10.1182/blood-2007-01-068148

Shlyakhtina, Y., Moran, K. L., and Portal, M. M. (2019). Asymmetric inheritance of cell fate determinants: focus on RNA. Noncoding RNA 5:E38. doi: 10.3390/ ncrna5020038
Singh, A. M., Sun, Y., Li, L., Zhang, W., Wu, T., Zhao, S., et al. (2015). Cell-cycle control of bivalent epigenetic domains regulates the exit from pluripotency. Stem Cell Rep. 5, 323-336. doi: 10.1016/j.stemcr.2015.07.005

Smits, L. M., Reinhardt, L., Reinhardt, P., Glatza, M., Monzel, A. S., Stanslowsky, N., et al. (2019). Modeling Parkinson's disease in midbrain-like organoids. NPJ Parkinsons Dis. 5:5.

Smyth, J. T., Schoborg, T. A., Bergman, Z. J., Riggs, B., and Rusan, N. M. (2015). Proper symmetric and asymmetric endoplasmic reticulum partitioning requires astral microtubules. Open Biol. 5:150067. doi: 10.1098/rsob.150067

Staretz-Chacham, O., Choi, J. H., Wakabayashi, K., Lopez, G., and Sidransky, E. (2010). Psychiatric and behavioral manifestations of lysosomal storage disorders. Am. J. Med. Genet. B Neuropsychiatr. Genet. 153B, 1253-1265. doi: 10.1002/ajmg.b.31097

Starling, G. P., Yip, Y. Y., Sanger, A., Morton, P. E., Eden, E. R., and Dodding, M. P. (2016). Folliculin directs the formation of a Rab34-RILP complex to control the nutrient-dependent dynamic distribution of lysosomes. EMBO Rep. 17, 823-841. doi: 10.15252/embr.201541382

Tee, A. R., Manning, B. D., Roux, P. P., Cantley, L. C., and Blenis, J. (2003). Tuberous sclerosis complex gene products, tuberin and hamartin, control mTOR signaling by acting as a GTPase-activating protein complex toward Rheb. Curr. Biol. 13, 1259-1268. doi: 10.1016/s0960-9822(03) 00506-2

TeSlaa, T., Chaikovsky, A. C., Lipchina, I., Escobar, S. L., Hochedlinger, K., Huang, J., et al. (2016). $\alpha$-ketoglutarate accelerates the initial differentiation of primed human pluripotent stem cells. Cell Metab. 24, 485-493. doi: 10.1016/j.cmet. 2016.07.002

Thelen, A. M., and Zoncu, R. (2017). Emerging roles for the lysosome in lipid metabolism. Trends Cell Biol. 27, 833-850. doi: 10.1016/j.tcb.2017.07.006

Todkar, K., Ilamathi, H. S., and Germain, M. (2017). Mitochondria and lysosomes: discovering bonds. Front. Cell. Dev. Biol. 5:106. doi: 10.3389/fcell.2017.00106

Tu, C., Zeng, Z., Qi, P., Li, X., Guo, C., Xiong, F., et al. (2018). Identification of genomic alterations in nasopharyngeal carcinoma and nasopharyngeal carcinoma-derived Epstein-Barr virus by whole-genome sequencing. Carcinogenesis 39, 1517-1528. doi: 10.1093/carcin/bgy108

Vardhana, S. A., Arnold, P. K., Rosen, B. P., Chen, Y., Carey, B. W., Huangfu, D., et al. (2019). Glutamine independence is a selectable feature of pluripotent stem cells. Nat. Metab. 1, 676-687. doi: 10.1038/s42255-019-0082-3

Venkei, Z. G., and Yamashita, Y. M. (2018). Emerging mechanisms of asymmetric stem cell division. J. Cell Biol. 217, 3785-3795. doi: 10.1083/jcb.201807037

Verdon, Q., Boonen, M., Ribes, C., Jadot, M., Gasnier, B., and Sagné, C. (2017). SNAT7 is the primary lysosomal glutamine exporter required for extracellular protein-dependent growth of cancer cells. Proc. Natl. Acad. Sci. U.S.A. 114, E3602-E3611. doi: 10.1073/pnas.1617066114

Villegas, F., Lehalle, D., Mayer, D., Rittirsch, M., Stadler, M. B., Zinner, M., et al. (2019). Lysosomal signaling licenses embryonic stem cell differentiation via inactivation of Tfe3. Cell Stem Cell 24, 257-270.e8. doi: 10.1016/j.stem.2018. 11.021

Vonk, W. I. M., Rainbolt, T. K., Dolan, P. T., Webb, A. E., Brunet, A., and Frydman, J. (2020). Differentiation drives widespread rewiring of the neural stem cell chaperone network. Mol. Cell 78, 329-345.e9. doi: 10.1016/j.molcel.2020.03.009

Walker, E., Ohishi, M., Davey, R. E., Zhang, W., Cassar, P. A., Tanaka, T. S., et al. (2007). Prediction and testing of novel transcriptional networks regulating embryonic stem cell self renewal and commitment. Cell Stem Cell 1, 71-86. doi: 10.1016/j.stem.2007.04.002

Wang, C., Haas, M. A., Yang, F., Yeo, S., Okamoto, T., Chen, S., et al. (2019). Autophagic lipid metabolism sustains mTORC1 activity in TSC-deficient neural stem cells. Nat. Metab. 1, 1127-1140. doi: 10.3390/ijms19051474

Wang, L., Huang, D., Huang, C., Yin, Y., Vali, K., Zhang, M., et al. (2017). Enhanced human somatic cell reprogramming efficiency by fusion of the MYC transactivation domain and OCT4. Stem Cell Res. 25, 88-97. doi: 10.1016/j.scr. 2017.10.014

Wang, S., Xia, P., Ye, B., Huang, G., Liu, J., and Fan, Z. (2013). Transient activation of autophagy via Sox2-mediated suppression of mTOR is an important early step in reprogramming to pluripotency. Cell Stem Cell 13, 617-625. doi: 10. 1016/j.stem.2013.10.005

Wells, C. A., and Choi, J. (2019). Transcriptional profiling of stem cells: moving from descriptive to predictive paradigms. Stem Cell Rep. 13, 237-246. doi: 10.1016/j.stemcr.2019.07.008 
Wu, Y., Li, Y., Zhang, H., Huang, Y., Zhao, P., Tang, Y., et al. (2015). Autophagy and mTORC1 regulate the stochastic phase of somatic cell reprogramming. Nat. Cell Biol. 17, 715-725. doi: 10.1038/ncb3172

Wyant, G. A., Abu-Remaileh, M., Wolfson, R. L., Chen, W. W., Freinkman, E., Danai, L. V., et al. (2017). mTORC1 activator SLC38A9 is required to efflux essential amino acids from lysosomes and use protein as a nutrient. Cell 171, 642-654.e12. doi: 10.1016/j.cell.2017.09.046

Xia, M., Zhang, Y., Jin, K., Lu, Z., Zeng, Z., and Xiong, W. (2019). Communication between mitochondria and other organelles: a brand-new perspective on mitochondria in cancer. Cell Biosci. 9:27.

Yang, H., Jiang, X., Li, B., Yang, H. J., Miller, M., Yang, A., et al. (2017). Mechanisms of mTORC1 activation by RHEB and inhibition by PRAS40. Nature 552, 368-373. doi: 10.1038/nature25023

Young, N. P., Kamireddy, A., Van Nostrand, J. L., Eichner, L. J., Shokhirev, M. N., Dayn, Y., et al. (2016). AMPK governs lineage specification through TFEBdependent regulation of lysosomes. Genes Dev. 30, 535-552. doi: 10.1101/gad. 274142.115

Zhang, C.-S., Jiang, B., Li, M., Zhu, M., Peng, Y., Zhang, Y.-L., et al. (2014). The lysosomal v-ATPase-Ragulator complex is a common activator for AMPK and mTORC1, acting as a switch between catabolism and anabolism. Cell Metab. 20, 526-540. doi: 10.1016/j.cmet.2014.06.014

Zhang, J., Khvorostov, I., Hong, J. S., Oktay, Y., Vergnes, L., Nuebel, E., et al. (2011a). UCP2 regulates energy metabolism and differentiation potential of human pluripotent stem cells. EMBO J. 30, 4860-4873. doi: 10.1038/emboj. 2011.401

Zhang, J., Lian, Q., Zhu, G., Zhou, F., Sui, L., Tan, C., et al. (2011b). A human iPSC model of Hutchinson Gilford Progeria reveals vascular smooth muscle and mesenchymal stem cell defects. Cell Stem Cell 8, 31-45. doi: 10.1016/j.stem. 2010.12.002

Zhang, J., Zhao, J., Dahan, P., Lu, V., Zhang, C., Li, H., et al. (2018). Metabolism in pluripotent stem cells and early mammalian development. Cell Metab. 27, 332-338. doi: 10.1016/j.cmet.2018.01.008

Zhou, J., Su, P., Wang, L., Chen, J., Zimmermann, M., Genbacev, O., et al. (2009). mTOR supports long-term self-renewal and suppresses mesoderm and endoderm activities of human embryonic stem cells. Proc. Natl. Acad. Sci. U.S.A. 106, 7840-7845. doi: 10.1073/pnas.0901854106

Zhu, L., Sun, C., Ren, J., Wang, G., Ma, R., Sun, L., et al. (2019). Stressinduced precocious aging in PD-patient iPSC-derived NSCs may underlie the pathophysiology of Parkinson's disease. Cell Death Dis. 10:105. doi: 10.1038/ s41419-019-1313-y

Zhu, S., Li, W., Zhou, H., Wei, W., Ambasudhan, R., Lin, T., et al. (2010). Reprogramming of human primary somatic cells by OCT4 and chemical compounds. Cell Stem Cell 7, 651-655. doi: 10.1016/j.stem.2010.11.015

Conflict of Interest: The authors declare that the research was conducted in the absence of any commercial or financial relationships that could be construed as a potential conflict of interest.

Copyright (c) 2020 Julian and Stanford. This is an open-access article distributed under the terms of the Creative Commons Attribution License (CC BY). The use, distribution or reproduction in other forums is permitted, provided the original author(s) and the copyright owner(s) are credited and that the original publication in this journal is cited, in accordance with accepted academic practice. No use, distribution or reproduction is permitted which does not comply with these terms. 